\title{
Lung protective strategy and prone ventilation resulting in successful outcome in a patient with ARDS due to H1N1
}

\author{
Dipankar Sarkar, Shruti Sarkar, Shweta Anand, Anju Kapoor \\ Department of Pediatrics, People's College of Medical Science and Research Centre, Bhanpur, Bhopal, Madhya Pradesh, India
}

Correspondence to Dr Dipankar Sarkar, dipankarshruti@gmail.com

\begin{abstract}
Summary
Acute respiratory distress syndrome (ARDS) is an acute respiratory condition caused by various pulmonary and extrapulmonary conditions including H1N1 virus infection. ARDS has a high mortality worldwide and in India various studies suggest that mortality in children is as high as $73-75 \%$. Different lung protective ventilation strategies have recently been adopted to reduce mortality. The authors report a successful outcome in a 3.5-year-old child with ARDS secondary to H1N1 infection following use of a very low tidal volume $(4-6 \mathrm{ml} / \mathrm{kg})$ along with high positive end-expiratory pressure breathing and prone ventilation. As far as we are aware, this is the first case report of a successful outcome in a child with ARDS secondary to H1N1 in India.
\end{abstract}

\section{BACKGROUND}

Acute respiratory distress syndrome (ARDS) due to pulmonary or extrapulmonary causes has high mortality worldwide and has been the most common cause of death in the current H1N1 pandemic. Use of a lung protective strategy resulted in successful outcome in a child with ARDS due to H1N1 in the high risk group for mortality.

\section{CASE PRESENTATION}

A 3.5-year-old child was referred to our hospital for intensive care support. He had a 3-day history of mild fever, cough and cold and a 2-day history of progressive respiratory distress. He also complained of throat pain and had been eating very little for the past 2 days. He was an only child, had been vaccinated appropriately and had normal development. His father had had a cough and cold a week previously and neither the child nor the father had recently travelled long distance.

On arrival, the child appeared very unwell, and was drowsy and centrally cyanosed. He was well nourished and weighed $15 \mathrm{~kg}$. He was saturating $30 \%$ in room air and $60 \%$ with $15 \mathrm{l} / \mathrm{min}$ oxygen. He had severe chest recession with a respiratory rate of $56 / \mathrm{min}$. On auscultation, he had diminished vesicular breath sounds along with bilateral crepitations. He had a good volume pulse at a rate of $146 / \mathrm{min}$ and his blood pressure was $98 / 52 \mathrm{~mm} \mathrm{Hg}$. He was immediately intubated with an uncuffed tube with fentanyl and midazolam adminstration and was ventilated with pressure controlled ventilation with a peak inflation pressure (PIP)/positive end-expiratory pressure (PEEP) of 32/7 and $\mathrm{FiO}_{2}$ of 1 .

\section{INVESTIGATIONS}

\section{Observation analysis and results}

The child was ventilated for 28 days and all blood gases $(n=63)$ were examined. For each test, the $\mathrm{PaO}_{2} / \mathrm{FiO}_{2}$ ratio was calculated. These $\mathrm{PaO}_{2} / \mathrm{FiO}_{2}$ values were statistically analysed before and after the application of prone ventilation and use of methylprednisolone using the t test. $\mathrm{PaO}_{2} / \mathrm{FiO}_{2}$ values were also statistically analysed comparing application of high $\mathrm{PEEP}^{1-4}$ and very high $\mathrm{PEEP}^{5-10}$ using the t test. The child's $\mathrm{PaO}_{2} / \mathrm{FiO}_{2}$ value was 49 during admission, which is indicative of severe hypoxaemia. The mean $\mathrm{pH}, \mathrm{PaO}_{2}$ and $\mathrm{PCO}_{2}$ were $7.43 \pm 0.10,77 \pm 26$ and $51 \pm 16$, respectively. Mean $\mathrm{PaO}_{2} / \mathrm{FiO}_{2}$ was $131 \pm 91$ (range 627-49). Mean $\mathrm{PO}_{2} / \mathrm{FiO}_{2}$ before and after prone ventilation was $122(n=23)$ and $135(n=40)$, respectively. Although the $\mathrm{PO}_{2} / \mathrm{FiO}_{2}$ mean value was higher after prone ventilation was started, the difference was not statistically significant ( $p>0.5$ ). The mean $\mathrm{PO}_{2} / \mathrm{FiO}_{2}$ values with high $\mathrm{PEEP}{ }^{1-4}$ $(n=35)$ and very high PEEP $(\geq 11)(n=25)$ were $158 \pm 112$ and $93 \pm 24$, respectively. Although clinically we felt that higher $\mathrm{PEEP} \geq 11$ was beneficial in improving oxygenation, the mean $\mathrm{PaO}_{2} / \mathrm{FiO}_{2}$ was lower with higher PEEP. The $\mathrm{PaO}_{2} / \mathrm{FiO}_{2}$ results did not improve after starting methylprednisolone and the mean $\mathrm{PaO}_{2} / \mathrm{FiO}_{2}$ values before and after starting methylprednisolone were $123 \pm 47(n=21)$ and $109 \pm 53$ ( $n=37$ ), respectively. The deterioration in $\mathrm{PaO}_{2} /$ $\mathrm{FiO}_{2}$ after methylprednisolone administration was statistically significant $(\mathrm{p}=0.02)$.

\section{TREATMENT}

The patient was immediately intubated with an uncuffed tube with fentanyl and midazolam administration and was ventilated with pressure controlled ventilation with a PIP/PEEP of $32 / 7$ and $\mathrm{FiO}_{2}$ of 1 . His saturation improved to $>90 \%$ and the first arterial blood gas analysis showed $\mathrm{pH}$ 7.31, $\mathrm{PaO}_{2} 49, \mathrm{PCO}_{2} 51$ and base excess (BE) of (-1.3). Chest $\mathrm{x}$-ray was consistent with ARDS (figure 1). The first $\mathrm{PaO}_{2} / \mathrm{FiO}_{2}$ ratio of 49 put him in the very high mortality risk category. Oseltamivir was started as the chance of H1N1 being the cause of ARDS was very high and a throat swab was sent for H1N1 analysis. In the next few days his ventilatory requirements were persistently high with high $\mathrm{FiO}_{2}$ while $\mathrm{PaO}_{2} / \mathrm{FiO}_{2}$ was persistently below 150 . He was ventilated with a moderately high PEEP of 7-10 and 


\section{BMJ Case Reports}

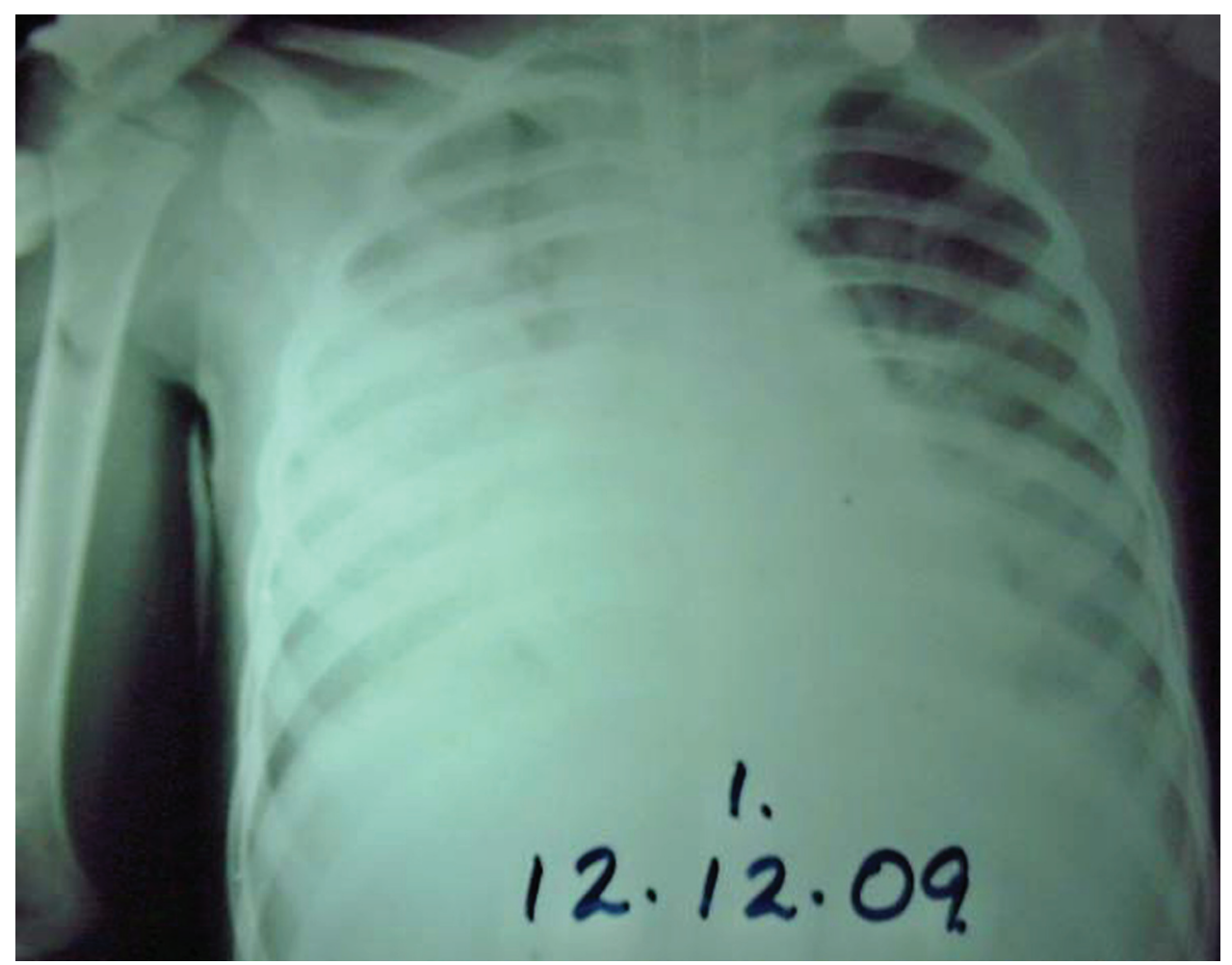

Figure 1 Chest x-ray soon after admission.

a PIP between 26 and 32. He developed gastric haemorrhage which was treated with pantoprazole. On day 4 of admission, the throat swab for H1N1 came back positive. In addition to oseltamivir, the patient also received broadspectrum antibiotics. He was kept under deep sedation and paralysis with fentanyl, midazolam and vecuronium infusions which were continued for the entire period of ventilatory support as it was difficult to keep his saturations up to $89 \%$ or $90 \%$ whenever sedation was decreased. The ventilatory requirements were closely titrated by regular arterial blood gas estimation. Enteral nutrition was stared early on day 5 of admission with 3-hourly nasogastric milk feeds to which sugar and protein supplements were also added a few days later. In the first week there was very little improvement in the ventilatory requirements or the hypoxaemia. The $\mathrm{PaO}_{2} / \mathrm{FiO}_{2}$ ratio continued to be below 150 , only occasionally increasing above 150 . There was further deterioration in chest x-ray with increased infiltrates and opacities. To treat hypoxaemia and deteriorating ventilation, the following strategies were applied. The patient was intubated with a cuffed endotracheal tube to prevent air leak. The standard lung protective strategy for ventilation was adopted but with higher PEEP, a lower tidal volume. We aimed at a target tidal volume of 4-6 $\mathrm{ml} / \mathrm{kg}$. We also applied prone ventilation on day 9 of admission, keeping the patient prone for $8 \mathrm{~h}$ in a 12-h cycle. Our paediatric ventilator had only pressure control mode with three basic modes of synchronised intermittent mandatory ventilation (SIMV), IMV and assist control mode and did not have any volume control mode but showed the pressure-volume curve and both the inspired and expired tidal volumes. Therefore, we progressively increased PEEP to a maximum of 16 with the aim of reducing $\mathrm{FiO}_{2}$ and maintained a PIP of not more than 34 , targeting a tidal volume of 4-6 m1/ kg. We had to increase the PIP up to 40 at times to deliver the targeted tidal volume. Methylprednisolone was added on day 10 at a dose of $2 \mathrm{mg} / \mathrm{kg} /$ day and was given for a total duration of 2 weeks. In the second week of ventilation, the patient developed high grade fever. The antibiotics were changed according to endotracheal suction and tube tip culture sensitivity results to which he responded over next few days. He subsequently developed surgical emphysema on day 14 of ventilation which was treated conservatively, and pneumothorax on the right side on day 20 of ventilation which was managed by inserting an intercostal chest drain. He had developed hypotension following pneumothorax which was treated with dopamine and resolved in 2 days. Over the following 7 days his ventilatory requirements progressively reduced. He was extubated to face mask oxygen after 28 days of ventilation and was weaned off oxygen in another 15 days. He was discharged home after 50 days in hospital. At the time of discharge, he was completely normal with no neurological or pulmonary complications.

\section{OUTCOME AND FOLLOW-UP}

The patient was discharged home after 50 days in hospital. At the time of discharge, he was completely normal without any neurological or pulmonary complications. He has remained well and with no neurological sequelae when seen at follow-up.

\section{DISCUSSION}

According to the Ministry of Health and Family Welfare, Government of India report, as of $28^{\text {th }}$ February 2010, a total of 29652 cases of H1N1 have been confirmed in 
India, including 2366 cases under the age of 5 years and 1372 deaths. ${ }^{11}$ ARDS has a very high mortality worldwide. Mortality in the USA has been reported to vary between $15 \%$ and $72 \%$ with an overall mortality of $43 \%$, which, however, has decreased over the past decades. ${ }^{12}$ Worldwide, ARDS mortality from various case series is reported to be $35 \%$ in Australia and New Zealand, ${ }^{13} 83 \%$ in Malaysia, ${ }^{14} 20.4 \%$ in the Netherlands ${ }^{15}$ and $19 \%$ in Taiwan. ${ }^{16}$ The reported mortality from ARDS in children in India is as high as $73.3 \%{ }^{1}$ and $75 \% .^{2}$

In 328 paediatric patients with acute lung injury (ALI)/ ARDS, Flori et al found that the initial severity of hypoxaemia has a predictive value for identifying patients at high risk of prolonged mechanical ventilation and death. In fact, an inverse relationship between initial $\mathrm{PaO}_{2} / \mathrm{FiO}_{2}$ and mortality has been delineated where 28 out of 82 patients with a ratio of $<99$ died, 30 out of 136 patients with a ratio of 100-199 died and only 14 out of 110 with a ratio of 200-300 died. ${ }^{3}$ Our patient had an initial $\mathrm{PaO}_{2} / \mathrm{FiO}_{2}$ ratio of 49 , putting him in group with the highest risk of death. In the first week of ventilation the $\mathrm{PaO}_{2} / \mathrm{FiO}_{2}$ ratio was usually $<150$.

In patients with ARDS, lung protective strategies including permissive hypercapnea, higher PEEP and a lower tidal volume (usually $6-8 \mathrm{ml} / \mathrm{kg}$ ) have been shown to be effective in decreasing barotrauma, with faster extubation and improved survival. ${ }^{4-6}$ In a randomised study of 861 patients, mortality in the protective lung strategy group was $31 \%$ versus $39 \%$. $^{7}$ Use of a tidal volume of $<6 \mathrm{ml} / \mathrm{kg}$ was associated with improved survival at 28 days, a higher rate of weaning from mechanical ventilation and a lower rate of barotrauma in patients with ARDS. ${ }^{8}$ In our patient we used even lower tidal volumes of $4-6 \mathrm{ml} / \mathrm{kg}$ with a positive outcome. The maximum PEEP used in our patient was $16 \mathrm{~cm} \mathrm{H}$ O. Mean $\mathrm{PaO}_{2} / \mathrm{FiO}_{2}$ with high $\operatorname{PEEP}^{1-4}(\mathrm{n}=35)$ and very high $P E E P \geq 11(n=25)$ was $158 \pm 112$ and $93 \pm 24$, respectively. Although clinically we felt that higher PEEP $\geq 11$ was beneficial in improving oxygenation, the mean $\mathrm{PaO}_{2} / \mathrm{FiO}_{2}$ was lower with higher PEEP. This was possible because as soon as oxygenation started to improve the PEEP was lowered and subsequently good $\mathrm{PaO}_{2}$ values were observed even with lower PEEP. The mean $\mathrm{pH}, \mathrm{PaO}_{2}$ and $\mathrm{PCO}_{2}$ values were $7.43 \pm 0.10,77 \pm 26$ and $51 \pm 16$, respectively. Mean $\mathrm{PaO}_{2} / \mathrm{FiO}_{2}$ was $131 \pm 91$ (range 627-49). Mean $\mathrm{PCO}_{2}$ is indicative of permissive hypercapnia, while mean $\mathrm{PO}_{2}$ reflects acceptance of low $\mathrm{PO}_{2}$.

In adult patients with ALI/ARDS, the prone position is known to benefit oxygenation and ventilation. The possible mechanisms involved in improved oxygenation in prone ALI/ARDS patients are: (1) increased lung volumes; (2) redistribution of lung perfusion; and (3) recruitment of dorsal spaces with more homogeneous ventilation and perfusion distribution. ${ }^{9}$ However, a randomised controlled trial of prone versus supine ventilation in 102 paediatric patients with ARDS found no difference in ventilator-free days. ${ }^{10}$ In our patient, the $\mathrm{PaO}_{2} / \mathrm{FiO}_{2}$ ratio was higher after starting prone ventilation, although the difference was not statistically significant ( $p>0.5$ ) (the mean $\mathrm{PaO}_{2} / \mathrm{FiO}_{2}$ ratio was 122 before and 135 after starting prone ventilation).

The effects of low-dose prolonged methylprednisolone infusion ( $1 \mathrm{mg} / \mathrm{kg} /$ day vs placebo for 28 days) on lung function in patients with early severe ARDS were studied in a randomised double-blind placebo controlled trial in the intensive care units (ICUs) of five hospitals and it was found that the duration of mechanical ventilation and ICU length of stay were both reduced. ${ }^{17}$ In a randomised double-blind placebo controlled trial on 180 patients' use of methylprednisolone after 7 days of onset of ARDS, it was found that if used within 14 days of onset the oxygenation index improved and the number of ventilator-free and shock-free days reduced. However, when used after 14 days of onset, there was an increase in mortality. ${ }^{18}$ We started methylprednisolone on the 10th day of ventilation at $2 \mathrm{mg} / \mathrm{kg} /$ day according to the protocol of Meduri et al. ${ }^{19}$ However, as there was no clinically appreciable benefit we stopped it after 2 weeks. On statistical analysis also it was found that oxygenation worsened, as indicated by the statistically significant deterioration in the $\mathrm{PaO}_{2} / \mathrm{FiO}_{2}$ ratio $(\mathrm{p}=0.02)$.

In our patient, although the effect of very high PEEP and prone ventilation combined did not result in a statistically significant improvement in oxygenation, these two modalities together with a very low tidal volume of 4-6 $\mathrm{ml} / \mathrm{kg}$ and permissive hypercapnea, in light of low $\mathrm{PaO}_{2}$ having prevented multiorgan failure, resulted in a successful outcome in this child who according to the initial $\mathrm{PaO}_{2} /$ $\mathrm{FiO}_{2}$ ratio was at a very high risk for mortality. To the best of our knowledge, this is the first successful outcome of ARDS secondary to $\mathrm{H} 1 \mathrm{~N} 1$ in the paediatric age group to be reported from India.

\section{Learning points}

- A tidal volume as low as $4-6 \mathrm{ml} / \mathrm{kg}$ is effective in improving oxygenation in acute respiratory distress syndrome (ARDS).

- Prone ventilation improves oxygenation in children with ARDS.

- Lung protective strategies combining very low tidal volumes, prone ventilation, very high PEEP and permissive hypercapnea improved oxygenation and ventilation and resulted in a successful outcome in a child with H1N1 ARDS.

\section{Competing interests None.}

Patient consent Obtained.

\section{REFERENCES}

1. Chetan G, Rathisharmila R, Narayanan P, et al. Acute respiratory distress syndrome in pediatric intensive care unit. Indian J Pediatr 2009;76:1013-16.

2. Lodha R, Kabra SK, Pandey RM. Acute respiratory distress syndrome. Experience at a tertiary care hospital. Indian Pediatr 2001;38:1154-9.

3. Flori HR, Glidden DV, Rutherford GW, et al. Pediatric acute lung injury. prospective evaluation of risk factors associated with mortality. Am J Respir Crit Care Med 2005;171:995-1001

4. Vitali SH, Arnold JH. Bench-to-bedside review: ventilator strategies to reduce lung injury - lessons from pediatric and neonatal intensive care. Critical Care 2005;9:177-183.

5. Miller MP, Sagy M. Pressure characteristics of mechanical ventilation and incidence of pneumothorax before and after the implementation of protective lung strategies in the management of pediatric patients with severe ARDS. Chest 2008;134:969-73.

6. Petrucci $\mathbf{N}$, lacovelli W. Lung protective ventilation strategy for the acute respiratory distress syndrome. Cochrane Database Syst Rev 2007;3:CD003844

7. The Acute Respiratory Distress Syndrome Network. Ventilation with lower tidal volumes as compared with traditional tidal volumes for acute 


\section{BMJ Case Reports}

lung injury and the Acute Respiratory Distress Syndrome. N Engl J Med 2000:342:1301-8.

8. Amato MB, Barbas CS, Medeiros DM, et al. Effect of a protective-ventilation strategy on mortality in the acute respiratory distress syndrome. N Engl J Med 1998;338:347-54.

9. Pelosi P, Caironi P, Taccone P, et al. Pathophysiology of prone positioning in the healthy lung and in ALI/ARDS. Minerva Anestesio/ 2001:67:238-47.

10. Curley MAQ, Hibberd PL, Fineman LD, et al. Effect of prone positioning on clinical outcomes in children with acute lung injury: a randomized controlled trial. JAMA 2005:294:229-37.

11. Ministry of Health and Family Welfare. Pandemic Influenza - A(H1N1). http:// mohfw-h1n1.nic.in (accessed 1 Feb 2011)

12. Zambon M, Vincent JL. Mortality rates for patients with acute lung injury/ ARDS have decreased over time. Chest 2008;133:1120-7.

13. Erickson S, Schibler A, Numa A, et al. Acute lung injury in pediatric intensive care in Australia and New Zealand: a prospective, multicenter, observational study. Pediatr Crit Care Med 2007;8:317-23.
14. Norrashidah AW, Azizi BH, Zulfiqar MA. Acute respiratory distress syndrome in a paediatric intensive care unit. Med J Malaysia 1999:54:225-9.

15. Kneyber MC, Brouwers AG, Caris JA, et al. Acute respiratory distress syndrome: is it underrecognized in the pediatric intensive care unit? Intensive Care Med 2008:34:751-4.

16. Wang JD, Wang TM, Chi CS. Clinical spectrum of acute respiratory distress syndrome in a tertiary pediatric intensive care unit. Acta Paediatr Taiwan 2003;44:202-7.

17. Meduri GU. Methylprednisolone infusion in early severe ARDS results of a randomized controlled trial. CHEST 2007;131:954-63.

18. The National Heart, Lung, and Blood Institute Acute Respiratory Distress Syndrome (ARDS) Clinical Trials Network. Efficacy and safety of corticosteroids for persistent acute respiratory distress syndrome. N Engl J Med 2006;354:1671-84

19. Meduri GU, Headley AS, Golden E, et al. Effect of prolonged methylprednisolone therapy in unresolving acute respiratory distress syndrome: a randomized controlled trial. JAMA 1998;280:159-65.

This pdf has been created automatically from the final edited text and images.

Copyright 2011 BMJ Publishing Group. All rights reserved. For permission to reuse any of this content visit http://group.bmj.com/group/rights-licensing/permissions.

BMJ Case Report Fellows may re-use this article for personal use and teaching without any further permission.

Please cite this article as follows (you will need to access the article online to obtain the date of publication).

Sarkar D, Sarkar S, Anand S, Kapoor A. Lung protective strategy and prone ventilation resulting in successful outcome in a patient with ARDS due to H1N1. BMJ Case Reports 2011;10.1136/bcr.10.2010.3420, date of publication

Become a Fellow of BMJ Case Reports today and you can:

- Submit as many cases as you like

- Enjoy fast sympathetic peer review and rapid publication of accepted articles

- Access all the published articles

- Re-use any of the published material for personal use and teaching without further permission

For information on Institutional Fellowships contact consortiasales@bmjgroup.com

Visit casereports.bmj.com for more articles like this and to become a Fellow 